\title{
ENTRE A FLAUTA E O PIANO: A MÚSICA E A OCUPAÇÃO ESPACIAL NA OBRA O CORUJA, DE ALUÍSIO AZEVEDO
}

Maria Viana*

Resumo: Na obra O Coruja, de Aluísio Azevedo, podemos verificar as complexas relações sociais próprias de um país onde a colonização, baseada na monocultura e no trabalho escravo, favoreceu a existência do homem livre, mas dependente das relações de favoritismo. Este artigo tem como objetivo percorrer essa obra na tentativa analisar a ocupação dos espaços físicos e simbólicos pelas personagens centrais do romance, mas tendo como ponto de partida as referencias musicais que aparecem ao longo da trama.

Palavras-chave: Aluísio Azevedo. O Coruja. Favoritismo. Música.

Abstract: When closely analysing O Coruja, by Aluísio Azevedo, one can find the complex social relations of a country where the colonization, based on monocultural plantation and slave work promoted the existence of free men, but strongly dependent of favouritism. This article indent to wander this work and determine the symbolic relations of the physical space used by the main characters, always basing our study on the musical references appearing on the plot.

Keywords: Aluísio Azevedo. O Coruja. Favouritism. Music.

* É mestre pelo programa de Culturas e Identidades Brasileiras do Instituto de Estudos Brasileiros da Universidade de São Paulo, onde defendeu dissertação sobre a obra O Coruja, de Aluísio Azevedo, e Bacharel em Letras (Português/ Francês) pela FFLCH-USP. 
| 160 |

Entre a flauta e o piano...

\section{A flauta e o espaço externo e excludente}

O romance O Coruja tem início com a morte da mãe de André Miranda, já órfão de pai, que a partir de então vai morar com um padre até a idade de 10 anos, quando é enviado para um colégio interno. No internato já mostra sua grande vocação para o trabalho, quer seja ajudando o jardineiro, quer seja organizando os tomos da biblioteca.

Pouco afeito às amizades, nos intervalos entre o almoço e o jantar, André dedicava-se aos estudos, mas à tarde descia à chácara, "onde encontrava o Caixa-d'óculos às voltas com uma pobre flauta, dentro da qual soprava ele o velho repertório das músicas de seu tempo. Foi essa miserável flauta que acordou no coração de André o gosto pela música". (Azevedo, 1963, p. 27)

Mesmo sem ter significativo conhecimento sobre a matéria, o funcionário do internato se dispõe a ensinar o garoto a tocar e "lá passavam as últimas horas da tarde, a duelarem-se furiosamente com as notas mais temíveis que um instrumento de sopro pode dardejar contra a paciência humana". (Azevedo, 1963, p. 32)

É no pátio do colégio interno que o protagonista conhece Teobaldo, "menino de doze anos, muito bonito, elegante e criado com mimo. Falava melhor o inglês e o francês do que sua própria língua, porque estivera mais tempo em Londres do que no Brasil. Era detestado pelos colegas do colégio, pois se sentia a uma légua de distância o hábito de mandar e ser obedecido". (Azevedo, 1963, p. 36)

É justamente essa postura arrogante que desencadeia uma briga entre colegas, durante a qual Teobaldo é defendido por André, chamado pelos outros garotos de Coruja, devido à sua fealdade e seu jeito taciturno. Ambos acabam por ficar de castigo. É, portanto, no "cárcere escolar" que a amizade tem início. Sobretudo porque os privilégios de Teobaldo não foram retirados e, a pedido dele, André pôde levar consigo alguns livros e a flauta que o Caixad'óculos lhe emprestara. Além disso, Teobaldo recebe ali uma cesta de iguarias, enviada pela mãe, que são compartilhadas com o novo 
amigo. Essa expressão inesperada de afeto por parte de Teobaldo causa em André grande impacto:

\begin{abstract}
Era a primeira vez que se achava assim, em comunicação amistosa com seu semelhante; era a primeira vez que alguém o escolhia para confidente, para íntimo. E sua alma teve com a surpresa desse fato o mesmo gozo de impressões que experimentara ainda há pouco seu paladar com os saborosos doces até aí desconhecidos para ele. E o Coruja, a quem nada parecia impressionar, começou a sentir afeição por aquele rapaz, que era a mais perfeita antítese do seu gênio e da sua pessoa. (Azevedo, 1963, p. 37).
\end{abstract}

A expressão mais forte dessa amizade foi uma flauta e um tratado de música, que Teobaldo comprou para André, quando fora a passeio à cidade, na companhia do diretor do colégio. Instrumento que o Coruja levará consigo quando for passar as férias na fazenda do pai do amigo.

No entanto, como tocava muito mal, o instrumento, acaba sendo confiscado por D. Geminiana, tia de Teobaldo. Ao ver seu colóquio amoroso com o noivo Hipólito ser interrompido pelas tentativas do aprendiz, ela esconde a flauta, que só será restituída ao término das férias.

Pelo relatado, pode-se observar que os espaços ocupados pela flauta no romance são a chácara, o pátio da escola, o cárcere e o jardim da fazenda. Logo, o instrumento é relegado às áreas externas, já sinalizando que esse também será o lugar de excluído, ocupado por André ao longo da trama, como veremos mais adiante.

\title{
O piano e o espaço interno da socialização
}

Na segunda parte do romance, vamos encontrar os rapazes no Rio de Janeiro, onde se instalam em uma casinha em Matacavalos. É durante a arrumação desse lugar, que vemos Teobaldo 
$\mid 162$ |

Entre a flauta e o piano..

preocupado com o espaço que ocupará na sala, entre duas janelas, seu suntuoso piano.

Mobiliada com esmero, a peça impressionou a proprietária e locadora do prédio, dona Ernestina, a ponto de a mulher lhes propor que almoçassem e jantassem com ela, mediante pagamento de determinada mensalidade. E era no piano, em torno do qual Ernestina reunia duas ou três amigas, que Teobaldo tocava e, sem perceber, seduzia e era seduzido pela dona da casa.

Uma vez instalados, é preciso que Teobaldo escolha o que estudar e aí temos um diálogo entre os amigos, durante o qual fica evidente a dificuldade do rapaz em escolher um caminho. O que pode ser resumido na frase dita por ele ao final dessa conversa: "Entendo um pouco de desenho, um pouco de música, de canto, de poesia, de arquitetura, mas sinto-me tão incapaz de apaixonarme por qualquer dessas artes. Tudo me atrai; nada, porém, me prende!"' (Azevedo, 1963, p. 76).

André, que tanto estudara para os exames preparatórios, é reprovado, e torna-se professor particular para sobreviver. Enquanto isso, Teobaldo, que fora preparado pelo amigo para os exames, reconhece que não teve mérito para tanto, mas matriculase no curso de Medicina.

Duas notícias terríveis chegam ao mesmo tempo a Teobaldo: a morte da mãe e a falência do pai, que terá de hipotecar a fazenda para pagar as dívidas. É quando o jovem decide abandonar os estudos e procurar emprego, do que é dissuadido por André: “O meu caso é muito diverso; sou de poucas aspirações, não desejo ser mais do que um simples professor; tu, porém, tens direito a muito, e aqui em nossa terra a carta de doutor é a chave de todas as portas das boas posições sociais." (Azevedo, 1963, p. 114).

Certo apego à frase sonora e à palavra escrita com excesso de adjetivos e floreios contribuiu para que Teobaldo tivesse alguma expressão nos jornais da Corte. E é nas folhas matutinas que o jovem, que até conseguira ter uma peça teatral encenada, tenta empregar-se, sem conseguir qualquer colocação.

Se a situação de Teobaldo estava ruim, fica ainda pior quando seu pai, Emílio, não conseguindo enfrentar a morte da esposa e a 
falência, comete suicídio. Esses infortúnios fazem com que o jovem mergulhe em estado de profunda melancolia. Quando se entregava aos longos passeios e às leituras científicas ou "recorria ao piano e passava duas ou três horas a recordar o clássico repertório que aprendeu em casa da família". (Azevedo, 1963, p. 107).

No decorrer de toda a trama, a única ligação afetiva significativa de André é para com Teobaldo, por isso, ele não mede esforços para tirar o amigo do estado de desânimo no qual lhe lançaram os últimos acontecimentos. Mas o luto e a mágoa absorvem o filho do barão por quase um ano. E Teobaldo nada mais faz do que comer o pouco dinheiro que o pai falido the deixara, perdendo-se na contemplação e no amor.

Portanto, era André quem provia a casa do aluguel aos charutos do amigo, o que o levava a adiar o matrimônio com Inezinha, filha de uma lavadeira, dona Margarida.

Além desse alentado casamento, tinha o rapaz dois outros projetos: montar um colégio reformador, sem castigos corporais e sem terrores, baseado nas ideias de Pestalozzi e Froebel, e "fazer um epítome da história do Brasil, em que se expusessem os fatos pela ordem cronológica." (Azevedo, 1963, p. 121). No entanto, nenhum de seus projetos se realiza: não se casa com Inezinha, não publica seu livro e tampouco consegue comprar o colégio onde lecionava, mesmo quando uma ótima oportunidade se apresenta.

Ainda que não dependesse há bastante tempo dos favores de Teobaldo e pudesse, com seus próprios recursos, no caso sua força de trabalho e grande capacidade de economia, realizar seus projetos, a lealdade que despendia ao amigo era tal que sequer percebia que, ao socorrer financeiramente o outro, afastava-se cada vez mais de suas próprias conquistas.

A certa altura do romance, Teobaldo reencontra Leonilda, atriz com quem mantivera relações amorosas, que acabara de voltar da Europa. Apaixonada, ela insiste em dedicar-se somente a ele, mas aquele amor que para a loureira seria uma virtude, para Teobaldo era uma depravação moral. E de novo ele pergunta-se porque não se empregar "Fazer-se professor? Isso, porém, era tão precário, tão maçante e tão subalterno... Empregar-se na redação 
| 164 |

Entre a flauta e o piano..

de um jornal? Mas em qual? E como? A quem devia dirigir-se"? (Azevedo, 1963, p. 131). E cada vez mais ia se convencendo de que "lhe faltava competência para ganhar a vida" (Azevedo, 1963, p. 131).

Leonilda não mede esforços para reconquistar Teobaldo. Chega a alugar uma casinha em Santa Teresa. Nova, modesta, de aspecto encantador, onde lhe espera trajada com um singelo "vestidinho de chita".

Mas todas as tentativas para reter o amante junto de si são vãs. Ele sabe que, ao unir-se a ela, prejudicaria sua carreira, fosse ela qual fosse. Muito embora não se esforçasse para buscar trabalho, tinha uma vaga confiança no acaso; "um modo preguiçoso de desejar ser feliz". (Azevedo, 1963, p. 137). E são esses ideários que fazem com que Teobaldo veja no casamento com Branca, a filha do comendador, a saída para seus problemas financeiros.

\section{Entre a flauta e o piano, uma peça de Schubert}

A cena armada pelo narrador para a apresentação de Branca tem início com a entrada da preceptora da jovem, Mme. De Nangis, a quem Teobaldo conta que ama apaixonadamente a música e que toca piano. Já tendo conquistado a feição daquela que, ele sabe, tem sobre sua pretendida grande influência, seguem para outra sala, onde "duas rabecas, uma violeta e um violoncelo dispunhamse a executar uma serenata de Schubert." (Azevedo, 1963, p. 191). Em pouco tempo, sem exageros e frases pretensiosas, mas elegante e distinto, medindo as frases e os gestos, Teobaldo passa a ser o centro das atenções de todas as damas, inclusive de Branca.

Aluísio Azevedo era também dramaturgo e certamente tinha bons conhecimentos sobre a música produzida no seu tempo. Portanto, não foi por acaso que escolheu uma peça do romântico Schubert para servir de fundo musical para o primeiro encontro entre Teobaldo e Branca. "Para os românticos a música se torna sistematicamente a 'arte de exprimir os sentimentos por meio de sons'. A música para eles é uma confidente, a que confiam 
todos os seus ideais." (Andrade, 1977, p. 135). Bem o disse Mário de Andrade.

Enquanto Teobaldo dançava, ouvia música e conversava na casa do conselheiro; o pobre André tentava em vão conter as crises histéricas de Ernestina, que, depois da morte de seu "protetor", o Sr. Almeida, reaparece na trama e exige que Teobaldo reassuma a antiga relação com ela. A mulher acaba por matar-se, não sem antes escrever uma carta-testamento, deixando todos os seus bens para o ex-amante.

A despeito do remorso por ter repudiado Ernestina horas antes de ela cometer suicídio, Teobaldo não se furta do direito de lançar mão do pecúlio por ela deixado e, três páginas adiante, vamos encontrá-lo deleitando-se nos lençóis de Leonilda, para, em seguida, cortejar a filha do conselheiro.

Todavia, insuflado por Aguiar, primo de Branca, o pai da jovem é contra o casamento, que só se realizará mediante a fuga do casal. No que contarão com o apoio do Coruja, que abriga os amigos na casa de dona Margarida, além de emprestar dinheiro a Teobaldo para as despesas. Portanto, mais uma vez, para que o filho do barão realize seus projetos, André procrastina os dele.

\section{Os espaços e as ilusões perdidas}

A última parte da obra, tem início com a apresentação da casa em Botafogo, onde moram os recém-casados Teobaldo e Branca, a mesma de onde a jovem fugira para casar-se. Mas uma grande transformação se deu naquele espaço depois da morte do pai de Branca, que é combalido por uma congestão cerebral, ao saber de sua fuga.

Já se lhe não viram espetar do alto do frontispício as caducas telhas, negras e esborcinadas, por entre cujas choradas sobre o pano da parede, que nem baba por velha boca desdentada. Agora, sente-se ali a mão de quem entra na vida disposto a viver; desde o portão da chácara vão os olhos descobrindo em que se 
|166 |

Entre a flauta e o piano...

regalar; caminhos e estatuetas, globos de mil cores, caramanchões e pequenos bosques artificiais: tudo nos diz que ali reside agora gente feliz e moça. (Azevedo, 1963, p. 230.)

Toda a casa exalava luxo, dos jardins aos salões, mas a herança de Branca estava longe de ser o que supunha o ambicioso noivo, que, além disso, gastava muito mais do que podia. Por insistência de Teobaldo, André vai morar com eles, mas só aceita o convite sob a condição de ocupar o sótão, para onde leva sua pobre mobília de professor. E aqui podemos constatar que, como ocorreu no colégio interno e na casa em Mata-cavalos, André é confinado aos espaços menosprezados da habitação.

Temos nessa altura da narrativa um dos poucos diálogos em que os dois amigos falam abertamente de seus sentimentos. É durante essa conversa que André confessa sua dor por inspirar tanta repulsa nas pessoas:

- Não imaginas meu Teobaldo, quanto me dói cada vez mais esta terrível antipatia que inspiro a toda gente. Ainda há pouco, enquanto me falavas de tua mulher, dizia eu comigo: "Para que me hei de aproximar, para que hei de chegar para ela, se tenho plena certeza de que minha presença lhe é fatalmente penosa, e aborrecida?" (Azevedo, 1963, p. 243).

Ao ouvir essa confissão, Teobaldo aproxima André de Branca, apesar da resistência do amigo. A partir de então, talvez tenham sido aqueles os melhores momentos da sacrificada vida do professor: quando compartilhava algumas horas de sua dura vida de trabalho a ler Camões e Garrett para a esposa de Teobaldo. Era também nessas ocasiões que o Coruja "tomava da flauta e punha-se a tocar para a distrair; quase nunca, porém, o conseguia, porque o desgraçado tocava mal e sem inspiração." (Azevedo, 1963, p. 243).

Esse é o único momento do romance em que a flauta é tocada em um espaço interno e com um intuito de aproximação social. Todavia, além de denunciar claramente a pouca vocação de 
André para a música, o narrador é ainda mais cruel ao declarar que, se para André aqueles momentos eram os mais agradáveis de sua vida, "Entretanto o que Branca sentia por ele era menos estima do que uma certa espécie de condolência, que todo coração feliz e farto costumava votar aos desfalecidos da fortuna." (Azevedo, 1963, p. 243).

No entanto, a admiração de Branca por Teobaldo começa a ser maculada justamente quando ela observa a forma inescrupulosa como o marido se apropria das notas escritas por André para o seu compêndio da História do Brasil e as publica como sendo de sua autoria em revistas e jornais.

Mais uma vez Teobaldo se vê em dificuldades financeiras, agora perdera dinheiro aplicando no câmbio. Aguiar lhe empresta expressiva quantia, livrando-o da falência. Leonilda, de volta da Europa, e sabendo-o casado e feliz, escreve cartas anônimas, afirmando que Branca o traia com um amigo. Já que não teria o amor de Teobaldo, o intuito da loureira era destruir a vida conjugal do ex-amante.

Enquanto isso, Aguiar que não conseguira seduzir a prima, ameaça processar Teobaldo pela dívida, caso ela não aceite tornarse sua amante. Não tendo a quem recorrer, Branca conta seus infortúnios a André, que escuta as ameaças de Aguiar por detrás de uma cortina e paga, mais uma vez, as dívidas do amigo. Corroído pelo ciúme, Teobaldo chega em casa bem no momento em que Branca, agradecida, abraça André. O marido saca um revólver e atira no Coruja, acertando-lhe no calcanhar.

Desfeito os mal-entendidos, Teobaldo desculpa-se com o amigo, que mais uma vez perde suas economias e o sonho de comprar o colégio onde lecionava. Ficando ainda com um irremediável aleijão, resultante do tiro que recebera. Como se não bastasse, cansada de esperar por André, Inezinha casa-se com "Picuinha", um soldado raso alcoólatra, com quem terá dois filhos, antes que o marido, completamente corroído pelo álcool, seja internado em uma clínica.

Teobaldo envolve-se cada vez mais com a política. No entanto, seu sucesso político corresponde à sua decadência moral, 
|168|

Entre a flauta e o piano...

e o leitor acompanha seu envolvimento com a corrupção e os vícios inerentes a algumas relações de poder. Sobretudo porque esse declínio ético e moral contrasta com a virtude de André e as repreensões permanentes da esposa. "Assim, vista sob a perspectiva da ascensão política de Teobaldo, a narrativa perfaz um caminho ascensional, que tem início no internato, passa pela conquista da posição de deputado e chega à indicação do alto posto de Ministro de Estado." (Levin, 2005, p. 27).

Em contrapartida, André mora no sótão da casa de Botafogo, de onde sai sempre pelos fundos, para não ser notado pelas pessoas de bem que frequentavam a casa do amigo, que agora, muito preocupado com sua reputação e de olho na carreira política, paulatinamente, vai dedicando menos tempo ao Coruja, que já estava tornando-se um estorvo para sua ascensão social.

No dia da nomeação de Teobaldo a ministro, a casa está repleta de gente, e André se aproxima e acompanha a festa de longe, pelas vozes, pelas cortinas brancas, pelo tilintar das porcelas, percebe que aquele lugar não é para ele. "E foi com a garganta cerrada por um punho de ferro que o mísero desceu lentamente a escada, arrastando de degrau em degrau o seu pé aleijado pelo tiro. (Azevedo, 1963, p. 334).

Depois da internação de Picuinha, André, que se via na obrigação moral de ajudar dona Margarida e Inezinha, aceita o convite para ocupar um quartinho na casa das duas mulheres e toma para si toda a responsabilidade da casa.

O corpo, combalido pelo excesso de trabalho e pelo manquejar, tornava-o ainda mais grotesco. A maledicença de dona Margarida e suas vizinhas logo fizeram do inofencivo professor um terrível monstro, tão feio de alma quanto de corpo. Um corpo maltrapilho que manquejava pela cidade em busca de trabalho para sustentar a si e a prole de Inezinha.

André torna-se ainda mais casmurro e resmungão, sobretudo quando Teobaldo lhe diz sutilmente que era melhor que ele não fosse mais ao solar, iria ele à casa de dona Margarida quando quisesse ver o amigo. 
O que de fato ocorre uma vez, quando chega a prometer a André um trabalho e a publicação do compêndio de História do Brasil. Pela primeira vez André lhe pede algo: um trabalho qualquer na biblioteca. Mais uma promessa que Teobaldo jamais cumprirá.

A crise existencial finalmente acomete Teobaldo, que, do alto dos seus 40 anos, conclui nada ter feito, pois todos os seus talentos foram colocados a serviço apenas de sua excessiva vaidade. Essa situação é bem representada pela imagem de um espelho partido, como tão bem demonstra o narrador na seguinte passagem:

Seu ideal era um espelho, onde só a sua imagem se refletia; quebrado esse espelho, ele não tinha coragem de encarar os pedaços, porque em cada um via ainda, e só, a sua figura, mas tão reduzida e tão mesquinha que, em vez de lhe causar orgulho como outrora, causavalhe agora terríveis dissabores. (Azevedo, 1963, p. 167).

Nesses fragmentos de espelho, o que Teobaldo vê com melancolia amarga é o esfacelamento de uma vida inteira dedicada apenas aos ímpetos da vaidade. Essa tomada de consciência tardia deflagra uma crise moral que acaba levando-o à negação niilista da vida e do mundo e, consequentemente, à morte prematura.

No caso dele, toda a realidade é aniquilada, porque nada além da vaidade guiava seu ser excessivamente vaidoso. Como bem conclui o próprio personagem nas páginas finais do romance: "Ser tão pouco, quanto tanto se ambiciona; ambicionar tanto e ter certeza de nunca ir além da própria pequenez, é muito mais doloroso, é muito mais cruel do que ficar eternamente sucumbido ao peso da primeira ilusão!" (Azevedo, 1963, p. 347.)

Em contrapartida, as ilusões de André mal conseguiam sair do esboço. E para entender isso, basta recapitular os espaços ocupados por ele ao longo do romance: nasce em uma espelunca em algum rincão de Minas Gerais; é criado por um padreco que the oferece o catre mais duro da casa; é esquecido pelo diretor em uma saleta já no primeiro dia no orfanato, e só se faz lembrado quando dorme e ronca; trava amizade com Teobaldo em uma situação 
| 170 |

Entre a flauta e o piano...

de cárcere escolar; ocupa o quarto menor e menos confortável quando é inquilino de dona Ernestina; vive modestamente em um sótão, quando vai habitar com Teobaldo e Branca; e, como se não bastassem todas essas situações de exclusão, nas quais a ocupação do espaço sinaliza, sobretudo, uma inadequação tanto econômica quanto social, quando vai morar com os de sua classe, na casa de dona Margarida, ocupa um quartinho sujo e desconfortável.

A situação social de André e Teobaldo os diferencia e, em certa medida, contribui para a definição de suas personalidades. O filho do barão de Palmar paulatinamente torna-se um medalhão e a situação de favoritismo entre os dois não é unilateral, mas ambivalente. Nessa relação, o mais beneficiado acaba sendo Teobaldo e essa exploração se dá não apenas do ponto de vista monetário, mas também intelectual.

Durante anos, André tinha uma ideia fixa dominante escrever a História do Brasil: "obra esta a que ele se escravizara desde os seus vinte anos e da qual nunca se distraíra investigando sempre, inalteravelmente, com a calma e paciência de um sábio velho que se dedica ao trabalho só pelo prazer de trabalhar, sem a menor preocupação de elogio ou glória". (Azevedo, 1963, p. 289).

Cabe assinalar ainda que André era um homem livre. No entanto, não é por acaso que o narrador usa o verbo escravizar para se referir à dedicação visceral do Coruja à escrita dessa obra interminável. É como se, ao usar esse verbo, o narrador já deixasse indicada a usurpação intelectual que se dará um pouco adiante.

Nos capítulos finais do romance, acompanhamos a maneira inescrupulosa como Teobaldo se apropria das notas escritas pelo amigo, publicando-as sob pseudônimo, não sem antes imprimir nelas certa "forma literária":

As conscienciosas notas de André, floreadas pelas lantejoulas da retórica do outro, converteram-se no objeto da curiosidade pública.

Foi um verdadeiro sucesso; o jornal que as publicou viu a sua tiragem aumentada e os artigos, uma vez colecionados em volume, deram várias edições. Daí nasceu o prestígio de Teobaldo entre os homens 
públicos do seu tempo, que desde então começaram a respeitá-lo, se bem que o habilidoso jamais declarasse positivamente ser o autor dos célebres artigos. (Azevedo, 1963, p. 291).

A linguagem pragmática usada por André é substituída por outra, floreada e retórica. Ou seja, os dados para construir a História do Brasil, coligidos pelo árduo trabalho intelectual de André, foram modificados pelas mãos aristocráticas de Teobaldo, que imprimiram neles os floreios necessários para que fossem aceitos pela opinião pública.

Diante do olhar sempre indignado de Branca, Teobaldo jamais assumirá publicamente a autoria dos textos, mas, graças à maneira pouco clara como fala sobre o assunto quando perguntado a respeito, acaba sendo considerado o autor das publicações. André tampouco o desmente, a despeito das insistências de Branca nesse sentido.

O capital econômico de Teobaldo foi solapado em várias situações, mas o capital simbólico de que é investido, graças à formação que tivera, como sua maneira aristocrática de se portar socialmente, contribuíram para sua ascensão política e social. Contudo, a coroação disso vem justamente com a publicação desses artigos inspirados nas notas de André.

No ensaio "As ideias fora do lugar", Roberto Schwarz declara que, cada um a sua maneira, os escritores brasileiros do século XIX deixaram refletir em suas obras o hábito do favor como uma mediação quase universal, baseando nele sua interpretação do Brasil. Isso, em certa medida, criava um acordo tácito entre as partes:

No momento da prestação e da contraprestação particularmente o instante-chave do reconhecimento recíproco - a nenhuma das partes interessa denunciar a outra, tendo embora a todo instante os elementos necessários para fazê-lo. Esta cumplicidade sempre renovada tem continuidades sociais mais profundas, que lhe dão peso de classe: no contexto brasileiro, o 
$\mid 172$ |

Entre a flauta e o piano...

favor assegurava às duas partes, em especial à mais fraca, de que nenhuma era escrava. (Schwarz, 2008, p. 11)

Essa situação paradoxal, tão bem expressa por Schwarz, talvez explique por que Teobaldo se apropria com certa naturalidade do trabalho intelectual de André; homem livre, pertencente a uma classe social economicamente desfavorecida, que, desde a infância, estabelecera com o amigo uma relação pautada na subserviência.

\section{Considerações finais}

Como vimos no decorrer desta análise, a flauta e seu tocador ocupam os espaços simbolicamente menos importantes na narrativa: o pátio da escola, a chácara, o cárcere escolar, os jardins das fazendas do pai de Teobaldo. O único momento em que o instrumento é tocado em espaço valorizado socialmente é quando André tenta distrair Branca, mas seu objetivo não é alcançado.

Em contrapartida, o espaço ocupado pelo piano na trama é privilegiado, tanto espacialmente, pois tem lugar de destaque nas casas onde Teobaldo mora, como simbolicamentes, pois é usado como marca da posição social privilegiada do filho do barão dentro do romance.

Se estamos de acordo que a arte tem função importante nos processos formativos, para André a proximidade com a música deu-se ao acaso e seu aprendizado ocorreu de maneira fortuita, pelas mãos de um homem que pouco entendia da matéria. Já no caso de Teobaldo, saber música, e sobretudo música clássica, fazia parte da formação aristocrática por ele recebida desde a infância. Ainda que essa manifestação artística não seja usada em compartilhamento estético com o coletivo, mas apenas para seduzir as mulheres que farão parte de sua educação sentimental. Como vimos, além de tocar para Branca durante o namoro e primeiros anos de casamento, o piano é citado com frequência durante o 
processo de sedução de d. Ernestina, proprietária da casa onde os rapazes moraram nos primeiros anos na Corte.

Se por um lado, a música praticada por André e o Caixa d'óculos era considerada um ruído, e as músicas populares tocadas pelo funcionário da escola só podiam ser executadas no pátio e na chácara; em contrapartida, o piano ocupava lugar de destaque nas salas da aristocracia e em torno dele aconteciam as reuniões sociais. Como bem aponta José Miguel Wisnik:

Tradicionalmente, um dos nós da questão na música esteve na separação, levada a efeito pelos grupos dominantes, entre a música "boa" e a música "má", entre a música considerada elevada e harmoniosa, por um lado, e a música considerada degradante, nociva e "ruidosa", por outro. Na verdade, isso se deve a que a própria idéia de harmonia, que é tão musical, apliquese desde longa data à esfera social e política, para representar a imagem de uma sociedade cujas tensões e diferenças estejam compostas e resolvidas. Do ponto de vista dominante, a contestação e a diferença aparecem como "ruídos", como cacófatos sociais, como dissonâncias a serem recuperadas segundo um código ideológico no qual muitas vezes a música oficial figura como sendo a demonstração "natural". (Wisnik, 2006, p.115).

Indo mais além, não apenas o instrumento do qual André tirava melodias populares era repudiado, como ele próprio, em diferentes situações, é excluído como um "cacófato social".

A despeito da derrocada moral no final da trama, Teobaldo sempre ocupa os espaços reservados à aristocracia rural a qual pertencia, tanto no que diz respeito ao locus real como ao simbólico. Por outro lado, no caso de André, a impossibilidade de firmar-se como pessoa nos três projetos por ele estabelecido não se concretizam. Não casou-se, não comprou a escola, onde colocaria em prática suas revolucionárias ideias pedagógicas, e tampouco publicou o livro sobre a História do Brasil. Esses três elementos, que 
podem ser vistos simbolicamente como o espaço da casa (família), o espaço do trabalho (escola) e o espaço da produção simbólica (livro) não foram conquistados, porque André os abandonadou, ou procrastinou, até que não pudessem mais ser realizados.

Podemos então afirmar que simbolicamente o espaço ocupado pela flauta dentro do romance desde as primeiras páginas, relegada aos espaços externos e desprestigiados socialmente, sinalizam o lugar que a personagem André também ocupará em toda a trama. Em contrapartida, o fato de o piano ser destaque nos ambientes frequentados por Teobaldo indica também a posição social privilegiada, desfrutada por ele, um filho da aristocracia rural, dentro da narrativa.

\section{Referências bibliográficas}

ANDRADE, M. Pequena História da Música. São Paulo : Martins, 1977.

AZEVEDO, A. O Coruja. São Paulo: Martins, 1963.

LEVIN, O. M. (Org.). Aluísio Azevedo. Fiç̧ão Completa, vols. I e II. Rio de Janeiro Aguilar, 2005.

SCHWARZ, R. Ao vencedor as batatas. São Paulo: Duas Cidades/ Editora 34, 2008.

WISNIK, J. M. Algumas questões de música e política no Brasil. In: Cultura Brasileira: Temas e situações. Org. Alfredo Bosi. São Paulo: Ática 2006. 